\title{
Molecular Basis of Neural Memory. Part 9: Defining the Engram
}

\author{
Gerard Marx ${ }^{1 *}$ and Chaim Gilon ${ }^{2}$ \\ ${ }^{1}$ MX Biotech Ltd., Israel \\ ${ }^{2}$ Institute of Chemistry, Israel \\ *Corresponding author: Gerard Marx, MX Biotech Ltd., Jerusalem, Israel

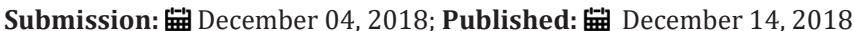

\begin{abstract}
A goal of neuroscientists is to identify the causal relationship between the functioning of neurons and the emergence of mental (psychic) states, such as emotions and memories. The notion that the basis for memory was due to physical changes in the brain, was first proposed by Richard Semon ( 1900), who also coined the term "engram" to refer to the physical trace of memory. Elements of Semon's concept are echoed nowadays in descriptions of "engram cells", neurons which supposedly store and recall the memory trace. But none of these identify the code that instigates the emotive states experienced and remembered by neural systems.
\end{abstract}

A mechanistic description of the phenomenon of recall (memory) should address key issues, such as:

- $\quad$ Identity of relevant physiologic compartments.

- Molecular features of encoding/decoding process.

- $\quad$ The process by which psychological (emotive) states are entangled with physiologic responses.

- Formalism (a theory) which reflects the physicality of neural encoding of cog-info.

We have proposed a tripartite mechanism that addresses the above issues, based on the dynamic interactions of 3 discrete physiologic compartments:

1. The neuron

2. Neural extracellular matrix (nECM) , the hydrogel around the cell which performs as its "memory material".

3. Trace metals and neurotransmitters (NTs) distributed therein (dopants).

The tripartite mechanism describes a chemical code for psychic states that is not linguistic, but presents the molecular correlates of the memory engram that render the neural synapse operative for the function of recall.

Keywords: Cognitive information; Emotion; Mentation; Trace metals; Neurotransmitters

\section{Background}

"Thinking" is a cognitive process associated with words like "mentation", "contemplation", "meditation", etc., all referring to the activity of the conscious "mind". Though much theologic, philosophic and psychoanalytic ink has been expended to describe "thinking" (with a literature to vast to cite), none has "grasped the nettle" of detailing how an assembly of neurons can instigate the psychic states that are the basis of our memories and conscious being.

The goal of neuroscientists has been to identify the causal relationship between the functioning of neurons and the emergence of mental (psychic) states, such as emotions and memories. The consensus is that neurons engage in electric synaptic signaling (action potentials), whose synaptic structures can be modified by learning, referred to as synaptic plasticity (SP) and long term potentiation (LTP). But this ignores the non-synaptic (ephaptic, volume transmission) signaling that is also a feature of neural communication [1-5]. In spite of many efforts, a formalization of the relationship between objective, external stimuli and internal subjective states that generate recall is still lacking.

\section{Memory and mind}

"unconscious mind is where all of our memories and past experiences reside."S. Freud [6]

Though Memory and Mind are inextricable qualities of the functioning brain, their connection still puzzles (Figure 1). While one can readily define "memory", particularly in this age of computers and memory chips, "mind is a much "stickier wicket". A valiant attempt to summarize thinking on the subject of "mind" was undertaken by Morris [7] a philosopher whose dissertation proposed a symbolic theory of mind. His later work summarized various theories of mind, categorizing them as: 

a) Mind as substance
b) Mind as process
c) Mind as relation
d) Mind as intentional act
e) Mind as substantitive
f) Mind as function.

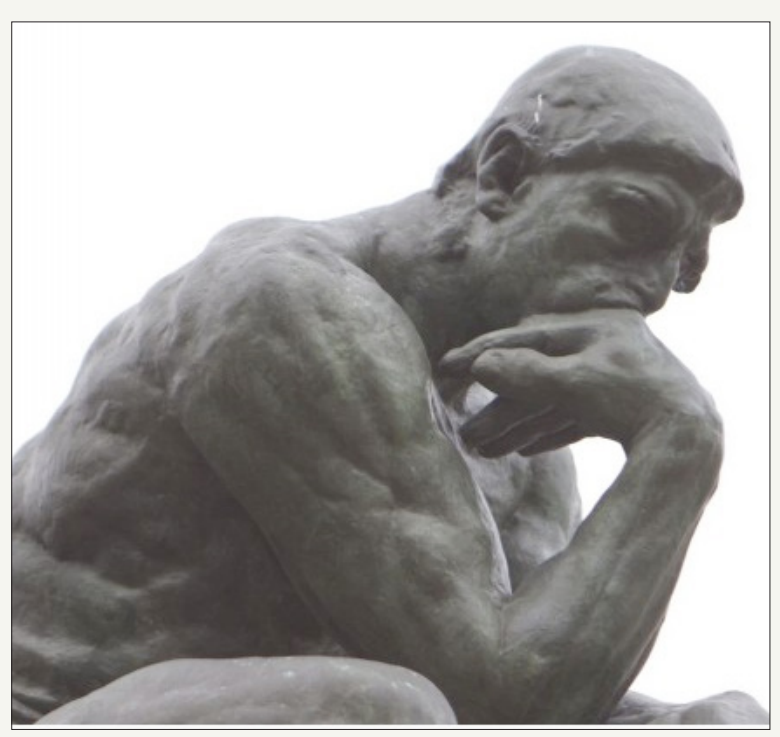

Figure 1: The thinker, sculpture by Rodin.

Though written in 1932, Morris' treatment focused mainly on philosophers (Aristotle, Descartes, Spinoza, Husserl, Russell, Shopenhauer, Nietze, Dewey, etc) but totally ignored the neurophysical realities of the neural system as described by Galvani ( 1790), Golgi and Cajal (circa 1900) and contemporary neuroscientists. He also did not allude to psychoanalytic theories of "mind" expressed by Freud, Jung and their like.

\section{Mind from matter}

Descartes, a French mathematician / philosopher (circa 1750) who coined the phrase "I think therefore I am", posed the mind/body duality problem that engaged the minds of eminent philosophers for more than 3 centuries (i.e. Spinoza, 1660, see: Matson [8] \& Ryle [9]). Unfortunately, philosophy is a poor platform for detailing biologic processes or for choosing from the above 6 descriptions of Mind.

We, a pair of chemists versed in the arcane knowledge of blood coagulation (GM) and psycho-pharmaceutical peptides (CG), are of the opinion that Mind, which is inextricably linked to memory, is both "substance" and "process". This is strangely analogous to Einstein's merging of the concepts of "space" and "time" into "spacetime", as will be discussed further along this narrative.

\section{Searching for the engram}

The notion that the basis for memory is due to external stimuli which produce enduring physical changes in the brain, was first proposed by Richard Semon, a German psychoanalyst. Semon invented the term "engram" to refer to a physical "trace" of sensorial stimuli embodied within the brain and available for recall [10]. The word is analogous to the tele-gram which refers to written text transmitted through telegraphy. Thus, Semon conceived that memory was inscribed/encoded in the brain, but couldn't delineate its material aspect.

The popularity of the term "engram" stems from a paper by Lashley [11] who appropriated the term though he did not cite Semon. Lashley worked for more than 30 year, using a combination of electrophysiologic techniques, surgery and animal training to search for the physiologic locus of the memory trace (with 20 publications). He concluded that he could not determine the site of the putative engram, though he ventured that it was diffused throughout the brain. Lashly's [11] work and lectures made the concept of the engram popular; but his citation oversight ensured that Semon and his book were almost forgotten [12].

\section{Modern hypotheses of the "engram"}

Elements of Semon's concept are echoed nowadays in descriptions of "engram cells", referring to neurons which supposedly store and recall the memory trace. For example, using a combination of optogenetics and other modern techniques, specific populations of "engram cells" have been identified [13]. "Engram cells" have been reported to underlie the addiction to cocaine [14], though the site-specific substrate or process has remained undefined [15]. It has been proposed that neural synaptic connections correlate with the "fear memory engram" [16,17]. Some infer an electrodynamic code among synaptically connected neurons [18]. Others suggest that memories are encoded by sparse populations of hippocampal "engram cells" operating as 2 prevailing models; one is that the hippocampal memory trace is based on the synaptic representations (maps) whose plasticity stabilizes them; an alternate theory is that the hippocampal memory trace is primarily an index to the memory stored in the neocortex [18-20].

But none of these studies addresses the issue of emotions: What kind of code or signaling is appropriate to describe the emotive states experienced by neural systems and remembered? They also suffer from presenting "naked neurons", not recognizing that neural shape reflects synaptic, as well as non-synaptic signaling through the neural extracellular matrix (nECM) surrounding them ( as recently reviewed Marx [5]).

\section{The engram revealed}

What is still lacking is a atomic-scale physical description of the encoding of cognitive information (cog-info), and storing it in a form available for recall by the neural circuit. A mechanism of the phenomenon of recall (memory) should conform to the composition and energetics of brain tissue and also address key issues, such as:

1. Identity of relevant physiologic compartments.

2. Molecular features of encoding/decoding cog-info.

3. A description of the process by which emotive states are achieved. 
4. Formalism (a theory) which reflects the physicality of neural encoding of cog-info.

In a series of articles, we proposed a tripartite mechanism to address some of the above issues [5]. It is based on the dynamic interactions of 3 physiologic compartments:

1. The neuron

2. Neural extracellular matrix (nECM) , the hydrogel around the cell which performs as its "memory material".

3. Trace metals and neurotransmitters (NTs) distributed therein (dopants).

These all are involved in the transformation of sensorial coginfo, into encoded [nECM/metal] complexes, molecular correlates of cognitive units of information (cuinfo), like computer bits. To some extent, it is analogous to the "memory materials" of computer chips [21-23].

We also introduced an iconographic notation to describe different types of metal-centered complexes called cuinfo (Figure 2) and cited many publications for detailed background material and supportive evidence. The tripartite mechanism describes a chemical code for psychic states not accessible to synthetic artifacts or simulations. It presents cuinfo as the molecular correlates of a memory engram that render the synapse operative. Essentially, the entire "edifice" of memory rests on the proper functioning of such a molecular encoding process.

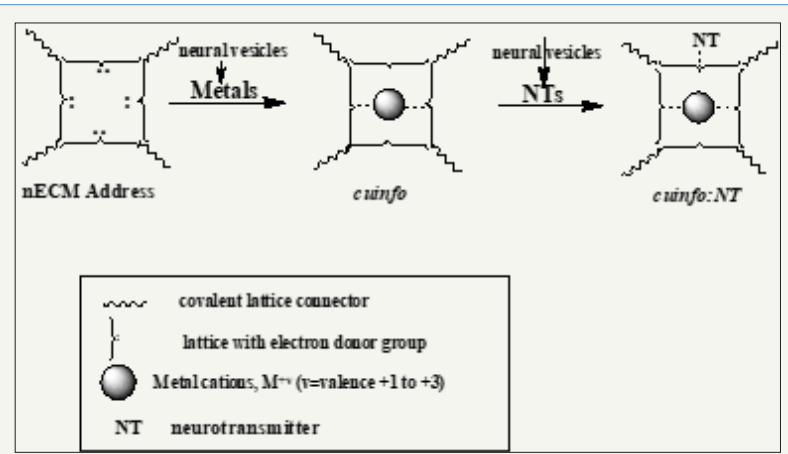

Figure 2: Chemographic representation of the tripartite mechanistic process, revealing the chemical composition of the cognitive units of information (cuinfo). It includes NTs which elicit physiologic reactions along with emotive states, which are remembered.

A cuinfo as well as an engram can both be characterized as [24]:

1. A persistent change in the brain which corresponds to a particular stimulus.

2. Manifest behaviorally and experientially.

3. May exist in a dormant state.

4. The physical (chemical) correlate of the emerging experience of recall.

The tripartite mechanism suggests that our experience of feelings are "engrammed" into cuinfo which are stored in the nECM. Unlike Champolion's decipherement of the Egyptian hieroglyphic
Rosetta Stone, we have no linguistic crib to decode the memory traces of neurons which elicit recall of emotive experiences.

\section{Heuristic implications}

As the information technology races to ever increasing the memory capacity of computer chips, it needs to develop new "memory materials" [21-23]. The above-described tripartite mechanism provides a psycho-chemical description of a neural memory system. The nECM performs as the 'medium of representation'; the dopants (metals and NTs) are the 'symbols of representation' [25].

Thus, we suggest that a synthetic polymer of select sulfated glycosaminoglycans (GAGs), be employed as a new "memory material". For example, polymers of disaccharide units of glucuronic acid (GlcA) and D-glucosamine (GlcN) which have been sulfated at the 4 or 6 position could be polymerized, to form the matrix [GlcAGlcN)] $]_{n}$. This could be exposed to dopant trace metals in a manner analogous to the use of metal dopants in silicon or carbon matrices in current chips [21-23, 31].

Such efforts would result in the development of a new class of neuromimetic memory devices. Success would also buttress the concept of the engram as a chemically-described memory trace.

\section{Acknowledgement}

(By GM). In memory of my wife, the artist Georgette Batlle (1940-2009), who provided emotional comfort for many years. Thanks to friends, Lilly Rivlin (New York, N.Y.) and the late Bill Needle (Eastchester, N.Y.) for their early encouragement and financial support in the period 1980-1984; I thank my nephew JJ Marx (Jerusalem) for suggesting that we include ideas for future research directions. Again, we wish to thank Professor Gallistel (Rutgers U.) for drawing our attention to "memory" as the proper focus of our speculations.

\section{Conflict of Interest}

GM is a founder of MX Biotech Ltd., with the commercial goal to develop new "memory materials".

CG is Emeritus Professor of the Institute of Chemistry, Hebrew University, Jerusalem, Israel. but is active in developing and patenting peptide-based tools for surgery and pharmacology. Notwithstanding, the ideas forwarded here are scientifically genuine and presented in good faith, without commercial clouding of the concepts expressed here.

\section{References}

1. Vizi ES, Fekete A, Karoly R, Mike A (2010) Non-synaptic receptors and transporters involved in brain functions and targets of drug treatment. Br J Pharmacol 160: 785-809.

2. Vizi ES (2013) Role of high-affinity receptors and membrane transporters in nonsynaptic communication and drug action in the central nervous system. Pharmacol Rev 52(1): 63-89.

3. Vargova L, Sykova E (2014) Astrocytes and extracellular matrix in extrasynaptic volume transmission. Phil Trans R Soc B 369(1654): 20130608. 
4. Agnati LF, Ferré S, Leo G, Lluis C, Canela EI, et al. (2004) On the molecular basis of the receptor mosaic hypothesis of the engram. Cell Mol Neurobio 24(4): 501-516.

5. Marx G, Gilon C (2018) The Molecular Basis of Neural Memory. Part: 10. The sins and redemption of neurobiology. J Neurology Neurocrit Care 1: 1-7.

6. Freud S (1899) The Interpretation of Dreams. Edition 1965, Avon Books: New York, USA

7. Morris CW (1932) Six theories of mind university Chicago press, Chicago Ill, USA.

8. Matson WI (1971) Spinoza's theory of mind the monist, 55: 567-578.

9. Ryle G (1948) The concept of mind. Hutchinson University Library, London.

10. Semon R (1923) Mnemic psychology, G Allen \& Unwin, London, UK.

11. Lashley KS (1950) In: search of the engram. Soc Experl Biol Symp No. 4: Physiological mechanisms in animal behaviour Cambridge, Cambridge University Press, England, UK, pp. 454-482.

12. Schacter DL (2001) Forgotten ideas, neglected pioneers: richard semon and the story of memory psychology Press, New York.

13. Tonegawa S, Liu X, Ramirez S, Redondo R (2015) Memory engram cells have come of age. Neuron 87(5): 918-931.

14. Hwa-Lin Hsiang, Jonathan RE, Michel C, van den Oever, Chen Yan, et al. (2014) Manipulating a cocaine engram in mice. J Neurosci 34: 1411514127.

15. Choi JH, Sim SE, Kim JI, Choi DI, Oh J, et al. (2018) Interregional synaptic maps among engram cells underlie memory formation. Science 360 $430-435$

16. Kwon JT, Choi JS (2009) Cornering the fear engram: Long term synaptic changes in the lateral nucleus of the amygdala after fear conditioning. J Neurosci 29: 9700-9703.

17. Kim JI, Choi DI, Kaang BK (2018) Strengthened connections between engrams encode specific memories. BMB Rep 51(8): 369-370.
18. Gelbard Sagiv H, Mukamel R, Harel M, Malach R, Fried I, et al. (2008) Internally generated reactivation of single neurons in human hippocampus during free recall. Science 332(5898): 96-102.

19. Santoro A, Frankland PW (2014) Chasing the trace. Neuron 84(2): 243246.

20. Tanaka KZ, He H, Tomar A, Niisato K, Huang AJY, et at. (2018) The hippocampal engram maps experience but not place. Science 361(6400): 392-397.

21. Di Ventra M, Pershin YY (2011) Memory materials: A unifying description. Materialstoday.

22. Chua LO (2011) Resistance switching memories are memristors. Applied Physics A 102: 765-783.

23. Zhou X, Xia M, Rao F, Wu L, Li X, et at. (2014) Understanding phasechange behaviors of carbon-doped $\mathrm{Ge}_{2} \mathrm{Sb}_{2} \mathrm{Te}_{5}$ for phase-change memory application. ACS Appl Mater Interfaces 6(16): 14207-14214.

24. Josselyn SA, Köhler S, Frankland PW (2015) Finding the engram. Nature Rev Neurosci 16(9): 521-534

25. Arbib MA (1987) Brains, machines and mathematics. (2nd edn), Springer Verlag, Berlin, Germany.

26. Bruce D (2001) Fifty years since lashley's in search of the engram: refutations and conjectures. J Hist Neurosci 10(3): 308-318

27. Collell G, Fauquet J (2015) Brain activity and cognition: a connection from thermodynamics and information theory. Front. Psychol 6: 818.

28. Marx G, Gilon C (2014) The molecular basis of memory. MBM Pt 3: Tagging with neurotransmitters (NTs). Front Aging Neurosci 6: 58.

29. Marx G, Gilon C, (2017) The molecular basis of neural memory. MBM Pt 7: Artificial intelligence (AI) versus neural intelligence (NI). AIMS Medical Science 4: 254-273.

30. Street S (2016) Neurobiology as information physics. Front Syst Neurosci 10: 90 .

31. Tian F, Jiao D, Biedermann F, Scherman OA (2012) Orthogonal switching of a single supramolecular complex. Nature Communications 3: 1207.
Creative Commons Attribution 4.0

International License

For possible submissions Click Here

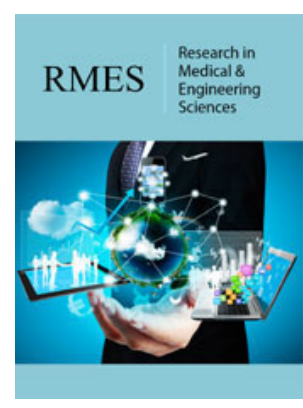

Research in Medicall \& Engineering Sciences

\section{Benefits of Publishing with us}

- High-level peer review and editorial services

- Freely accessible online immediately upon publication

- Authors retain the copyright to their work

- Licensing it under a Creative Commons license

- Visibility through different online platforms 